International Conference on Research in Education, Teaching and Learning

Paris, France| November 2 -4, 2018

\title{
Aspiration of Applicants for Studying At University and Their Confrontation with Reality of Study
}

\author{
Marta KOLARIKOVA \\ Silesian University in Opava/ Institute of Pedagogical and Psychological Sciences \\ Bezrucovo nam. 14, 74601 Opava, Czech Republic
}

\begin{abstract}
The paper focuses on the issue of achievement of success in university studies and factors that may adversely affect the future study success of applicants for higher education. It presents the practical research and its key conclusions, whose subject were 721 pupils of secondary schools in three of 14 regions of the Czech Republic. According to the findings, students are characterized by a certain diversity, in their expectations. Their attitudes are influenced by the current manner of continuous monitoring, and assessment of studies, the fulfillment of clearly defined duties and the low autonomy or responsibility required in previous levels of education. The research has shown that the greatest worries for university applicants lie in changing the system for obtaining important information, the possibility of preparing their own study plan, forms and methods of tuition, methods of assessment. Universities in the Czech Republic are not ready for the upcoming generation of students, who are used to using the so-called "new media", computer networks or individual web services (Internet search engines, social networks, blogs, wiki servers, etc.). On the other hand, they lack the ability to sort information by importance, and to evaluate its benefits. Keywords: aspiration, study, university, research, applicant
\end{abstract}


